\title{
Flaming Chalice of Hope: A Case Study of Suicide Prevention in a Faith Community ${ }^{\dagger}$
}

\section{Sally Spencer-Thomas}

United Suicide Survivors International, 10122 Buena Vista Drive, Conifer, CO 80433, USA; sallyspencerthomas@gmail.com

+ On 7 December 2004, my brother Carson died of suicide. Although I was the only person in my family who was a member of the Jefferson Unitarian Church, the senior minister at the time, Peter Morales, and the Pastoral Care Team took exceptionally good care of my family for the months that followed our tragedy. They helped create a memorial service that honored the life Carson lived while not shying away from the devastation his death left behind. They followed up with all immediate family members for months after his death and started many new mental health and suicide prevention initiatives in subsequent years. While many lessons have been learned, and we continue to evolve, I am deeply grateful for the unique way my faith community has led the effort to break down the silos between spiritual and emotional health.

Received: 7 January 2018; Accepted: 28 March 2018; Published: 11 April 2018

\begin{abstract}
The integration of spiritual and emotional health is key for the development of a comprehensive public health approach to suicide prevention. Faith communities play a unique and powerful role in shaping this integration. This case study investigated one United States-based, predominantly White Unitarian Universalist faith community's efforts in the development of promising practices for "upstream, midstream, and downstream" approaches to suicide prevention. Through a series of in-depth interviews with stakeholders (leadership, volunteers, family members with lived experience), response patterns were used to identify key strategies to promote mental health and prevent suicide. These key strategies include developing healthy social connectedness across one's life, finding ways to make meaning by connecting with something larger than oneself, and cultivating a community that is compassionate and knowledgeable when assisting its members through emotional crises.
\end{abstract}

Keywords: suicide; mental health; faith; religion; spirituality; resilience

\section{Introduction}

In most Western societies, religion plays a protective role against suicide death (Wu et al. 2015). For many, the ability to continue living or succumb to suicide and die can relate to aspects of their spiritual life such as religious coping, social support in religious communities, and specific teachings (Wu et al. 2015). Spiritual or religious frameworks can serve as explanatory models for life's experiences (Bonelli et al. 2012). For instance, religious beliefs can offer reasons for mattering, even when despair is great; conversely, religious beliefs also can be the cause for exacerbated guilt and shame.

As we learn more about the interplay among the mind, body, and spirit in suicide prevention, faith, religion, and spirituality become increasingly important components. Suicide is often the fatal outcome of untreated or mistreated mental illness, such as mood, anxiety or substance use disorders; faith communities can be crucial liaisons in connecting their members to life-saving mental health care including medication, talk therapy and, when suicidality is acute, hospitalization.

Additionally, faith communities can play an important role in providing support and meaning-making for people in despair. Many people turn to faith and their faith communities in times of crisis to help with healing. Others find that spiritual practices and a sense of belonging help 
them manage despair that can result from various mental health conditions such as mood and anxiety disorders, thought disorders, and substance use disorders. For these reasons, people who seek out spiritual or religious pathways as a part of coping would likely benefit from a collaborative approach between faith communities and mental health services (Spencer-Thomas 2010). This case study was undertaken to explore the lessons learned from an effort to integrate spiritual life and emotional life within one faith community.

\section{What Is the Difference between Religion and Spirituality?}

Spirituality is often experienced as personal and subjective, encompassing meaning and purpose in one's life (Colucci 2008). When people grow spiritually, they attach to something greater than the individual self; they often find a deep sense of connectedness beyond time and place. By contrast, religion is more formal, ritualized, and institutionalized. Throughout many faith traditions, religion is the most common cultural representation of spirituality (Colucci 2008).

For some, spirituality can be experienced outside of a faith community through transcendent connections to nature or the arts. For others, spirituality is experienced through the meaning-making of volunteer service or social justice work.

Religion can often provide structure through sacred texts, rituals, and creeds to help people find connection to a higher purpose, find comfort through life's hardships, and mark important milestones throughout the course of one's life.

Connecting these spiritual and religious experiences to a comprehensive approach to suicide prevention is the first step to appreciating how faith fits into a broader public health strategy. One study (Phend 2009) showed that attendance at religious services at least once a year halved the risk of suicide attempts, demonstrative of the protection one receives from belonging to a faith community. However, higher scores for spirituality and religious affiliation do not prevent suicide ideation, indicating that spirituality alone does not appear to be comprehensively protective (Phend 2009).

\section{What Is a Comprehensive Approach to Suicide Prevention?}

When it comes to helping people withstand life's overwhelming challenges, faith communities can help their members with prevention, effective intervention, and compassionate crisis response. In the world of public health, the following parable illustrates why a comprehensive approach to mental health promotion and suicide prevention is needed:

You are walking along a river one day and you hear a plea for help from someone drowning. You are startled but energized as you dive into the water and save him. Using all your strength you pull him to shore and start administering CPR (cardiopulmonary resuscitation). Your adrenaline is racing as he starts to regain consciousness. Just as you are about get back on your feet, another frantic call comes from the river. You can't believe it! You dive back in the river and pull out a woman who also needs life-saving care. Now a bit frazzled but still thrilled that you have saved two lives in one day, you mop the sweat from your brow. When you turn around, however, you see more drowning people coming down the river. One after another. You shout out to all the other people around you to help. Now there are several people in the river with you-pulling drowning people out left and right. One of the rescuers swims out to the drowning group and tries to start teaching them how to tread water. This strategy helps some, but not all. Everyone looks at each other, completely overwhelmed, wondering when this will stop. Finally, you stand up and start running upstream. Another rescuer glares at you and shouts, "Where are you going? There are so many drowning people; we need everyone here to help!" To which you reply, "I'm going upstream to find out why so many people are falling into the river.". (Spencer-Thomas 2016)

The focus of most suicide prevention and mental health crises is on pulling the "drowning people" out of the water. Many people in these rescue roles find themselves exhausted and resources are quickly depleted; yet, the suicide rates continue to climb (American Foundation for Suicide Prevention n.d.). 
Together, tenets of faith, rituals of religion, practices of spirituality, and communities of faith provide a unique contribution to add to the upstream, midstream, and downstream approaches. They build protective frameworks, such as resilience ("upstream prevention"), support emerging mental health and life challenges ("midstream intervention"), and respond to the tragedy of suicide and suicide attempts ("downstream crisis response").

\subsection{Upstream Suicide Prevention: Resilience and Social Support}

Upstream prevention focuses on bolstering protective factors, such as the core values of compassion and resilience, opportunities for social support and connectedness, and spiritual practices which also function as coping skills.

Resilience: Oxford English Dictionary (n.d.) defines resilience as "the capacity to recover quickly from difficulties." Faith communities and spiritual practices can have a profound effect on building resilience as well as the ability to bounce back after life's hardships. In most of the world's faith traditions, emphasis is placed on the value of life and compassion towards others (Doty and Spencer-Thomas 2012). These beliefs can offer reservoirs of perseverance when life gets hard.

Social Support: Faith communities provide a sense of integrated belonging, one in which a person can find deep connections. Additionally, many faith communities provide opportunities to serve causes for the common good. Community engagement and standing up against injustice are ways we gain perspective on our own lives as well as help us make meaning by giving back to the community.

Spiritual Practices: Spiritual and religious practices often help us to calm and center ourselves while promoting healthy lifestyles. For example, practices like prayer, chanting, and meditation can help us to feel grounded. Values of altruism, simplicity, or moderation help us to choose healthier ways of being.

These aspects of faith traditions and spirituality help us to build our resilience reserve. Consequently, when we experience overwhelming challenges like mental health conditions, injustice, or trauma, we are in a better position to cope and return to function rather than succumbing to hopelessness and suicidal despair.

\subsection{Midstream Suicide Prevention: Early Identification and Mental Health Promotion}

Faith communities also play an important role in identifying emerging suicidality and promoting mental health. They also help to connect people who are experiencing symptoms of despair to qualified mental health professionals. About $50 \%$ of mental health service consumers reported that their spiritual practices were central to how they lived with mental illness (Colucci 2008).

Religious beliefs and the strength of an individual's connection to those beliefs vary greatly. For some, extreme or oppressive religions or religions who hold unrealistic expectations for their members can increase risk and symptomatology (Colucci 2008). However, for many, a humanistic "brother's keeper" mindset helps members look out for one another. Within a community with shared goals of mutual assistance and support, faith community members may be in a position to better identify changes in an individual's behavior than other systems, e.g., the workplace. Changes in behavior, such as decreased attendance at faith community gatherings or emerging religious questions about death and dying, may indicate emerging risks for suicide that may be evident within a faith community. When observed, these warning signs provide opportunities for conversations about mental health and suicide among faith community members. Training to help faith community members learn best practices in suicide risk identification, support and referral often helps build the confidence and competence needed to navigate these conversations (QPR Institute n.d.).

For these reasons, faith communities potentially play a key role in an individual's recovery from mental health challenges. Knowing this, national mental health and faith associations in the U.S. have started to develop resources to bridge the silos between faith and mental health with the goal of helping faith communities improve their ability to identify members with emerging symptoms and link them to appropriate care. For example, the National Alliance on Mental Illness' (NAMI) Faith 
Net (www.nami.org/faithnet) and the Stephen Ministries (www.stephenministries.org) help equip faith communities to be welcoming to people experiencing tough times or mental health challenges. National Action Alliance for Suicide Prevention (2017) also developed guides to interfaith worship services, spiritual resources and even a "National Day of Prayer" to help promote suicide prevention efforts within traditional faith community practices.

\subsection{Downstream Suicide Prevention: Suicide Crisis Response}

For many, religion and spiritual practices are deeply embedded in the process of suicide bereavement. For some, the devastation of the tragedy causes them to "lose faith", while others find solace in their religious belief system. After a suicide, faith communities can be places of refuge and healing, but they can also be places of judgment. People tend to look to their faith as they work to make meaning after a loss, to explore their belief in the afterlife, and to wrestle with their spiritual struggles (Krysinska et al. 2017).

Although these theoretical arguments for the integration of emotional and spiritual health make sense, few case studies have demonstrated how they can be put into practice within a faith tradition or community. The purpose of this paper is to describe how one Unitarian Universalist church in Golden, Colorado USA developed a multi-pronged approach to break down the silos of religion and mental health.

\section{Methods}

\subsection{About Unitarian Universalism (UU) and the Jefferson Unitarian Church (JUC)}

Unitarian Universalism is a diverse and inclusive faith community that emerged from the blending of two Christian groups in 1961: the Universalists and the Unitarians. Today, the Universalist Unitarian community embraces many different groups and paths to truth. These "paths to truth" include many religious texts, such as the Bible, Qur'an, and Buddhist readings, and also welcome science and earth-based belief systems, such as Wicca, some Native American practices, and more (Unitarian Universalist Association n.d.). The tradition is not held together by a specific creed or religious doctrine but seven guiding principles (Unitarian Universalist Association n.d.):

1. "The inherent worth and dignity of every person";

2. "Justice, equity, and compassion in human relations";

3. "Acceptance of one another and encouragement to spiritual growth in our congregations";

4. " "A free and responsible search for truth and meaning;"

5. "The right of conscience and the use of the democratic process within our congregations and in society at large";

6. "The goal of world community with peace, liberty, and justice for all"; and

7. "Respect for the interdependent web of all existence of which we are a part." (https://www.uua. org/beliefs/what-we-believe/principles)

The Flaming Chalice is the symbol of the faith, and the lighting of the chalice is a ritual that is often practiced in many UU gatherings and worship services. The Flaming Chalice holds many sacred meanings for the faith community, specifically "the light of reason, the warmth of community, and the flame of hope" (Unitarian Universalist Association n.d.).

The Jefferson Unitarian Church was founded in 1959 in Golden, Colorado (USA) with 32 founding members (Prouty and Ray 2009). Today, JUC has upwards of 800 members, making it the 15th largest UU congregation in the world (Unitarian Universalist Association 2014). Membership is predominantly White, middle-class, and college-educated from rural, suburban and small city communities. 


\subsection{Subjects and Procedure}

A cross section of the JUC community was selected for a $1 \mathrm{~h}$ in-depth interview (three in-person interviews and six by phone).

Inclusion Criteria: Fifteen members of JUC were approached to participate in this project. Selected candidates had been active in the community of Jefferson Unitarian Church between 2004 and 2017 and represented diverse perspectives as stakeholders in the topic of suicide and mental health at JUC. Intentional outreach included JUC leadership, staff, and volunteer perspectives as well as people who had personal experience with suicide or a mental health crisis (either first-hand or as a caregiver). They were recruited with an email invitation from the researcher who is also a member of JUC. Of the 15 members invited, nine participated. Others did not respond or declined due to time constraints.

Subjects included two Senior Ministers, one Associate Minister, four family members that had experienced mental health/suicide crises, one pastoral caregiver, and one teen group advisor. Participants had played multiple roles in the church over the years and had also been impacted by mental health and suicide in various ways. For instance, two of the family members had also served as Church Board President. Four had volunteered in mental health/suicide prevention communities outside of church. Two had lost a first-degree relative to suicide.

Consent: Participants were given a written informed consent agreement and gave verbal consent to that agreement. Because of the nature of the case study's research, the study was not reviewed by an ethics committee.

Data Collection and Analysis: The researcher wrote down verbatim quotations during each of the interviews. These quotations were reviewed and organized into clusters on the basis of response patterns. The patterns and key quotations are reported in the results section.

\subsection{Questions}

- How do you describe Jefferson Unitarian Church (JUC) and your role in it?

- How have mental health/suicide issues shown up in your life and how does that play a role in your participation in mental health/suicide prevention/suicide loss work of the church?

- Is it possible to conceptualize suicide as a crisis of spirituality? What might the UU Church say about this that might be different than other faith traditions?

- What are the challenges many faith communities face when bringing together mental health and spiritual health? When addressing suicide prevention and suicide grief? Were these conversations ever a problem at JUC?

- Can you tell me a story about how JUC successfully navigated spiritual/emotional guidance related to suicide prevention/mental health promotion, intervention, crisis support, or suicide bereavement support

- What one JUC specific practice/event (related to mental health/suicide prevention/grief support) sticks out to you? Why? What have been the lessons learned from this practice/event?

\section{Results}

\subsection{Describe the Unitarian Universalist Faith and Jefferson Unitarian Church}

The faith tradition of Jefferson Unitarian Church (JUC) is Unitarian Universalism (UU). Most interviewees described Unitarian Universalism as a "liberal and progressive faith" that values science, values open mindedness, and focuses on social justice. Despite UU's foundations in Judeo-Christianity, the Church's spiritual and religious teachings are as likely to come from ancient Christian writing as they are from Buddhism, Native American ritual, Scientific American, and modern poetry. One church leader provided the following perspective of the religious leaning of the JUC community:

- $40 \%$ believe in some type of Judeo-Christian framework, even if they are pushing against it;

- $\quad 10-20 \%$ would identify as atheist/humanist and are science-driven in their search for truth; 
- $\quad 10-20 \%$ lean towards Buddhism and participate in the many meditation groups offered;

- $10 \%$ would be close to Wiccan or an earth-centered belief system;

- $10 \%$ say they are "nothing" and don't identify with any group.

Interviewees' descriptions of JUC clustered around four core themes: faith and science, community, social justice, and reciprocity. These aspects of religious life at JUC are associated with the sense of belonging and purpose so central to suicide risk reduction (Joiner 2006).

Faith and Science: Because UUs are able to simultaneously embrace both scientific and religious ideas, the faith community is home to many scientists and mental health professionals. These individuals may be more apt to examine research on suicide prevention instead of considering suicide a moral failing.

As one minister said, "We believe something greater than us individually, transcendent to us and present in each of us. Reason is a partner and not an opponent. We believe we can learn from what it means to be a living human being."

Another said, "What sets UUs apart is that we have a great respect for science. Our spirituality-science, nature, the universe-they all play a role. We look for truth and what can be factual. Some of us are 'if it's not a fact, I'm not going there' others can look beyond the facts."

Community: Several interviewees noted that the welcoming community is even more important than the faith teachings. In their own words, each participant mentioned how JUC had offered them a sense of belonging. For instance, "[JUC] is a place where like-hearted people come together to make connections, grow in faith, and lean on each other."

"There is a total acceptance of everyone. No matter how much they perceive themselves to be 'broken.' To me [fostering belonging is] one of the most important things that we do. The value of 'respect and dignity' for all has made me more open to others," commented one interviewee.

"We are a group of people who agree to companion each other on a journey," said another.

Social Justice: Standing up as a community for various social justice issues is one point of commonality at JUC. Some existing task forces include "Ethical Eating", "Gun Violence Reduction", and "The Green Task Force." One special project of the church is to raise funds to provide scholarships so that Guatemalan children impoverished by civil war can attend school.

One participant said, "Unitarian Universalism is a faith where people are concerned about the greater world. Here they find a purpose beyond themselves."

On minister put it this way, "We are spiritual centers with a civic circumference. Bound by our values, we grow into our best selves to serve as moral agents that shape shift our communities."

Reciprocity: Giving to the church in some way is important to many members and was another prevalent theme in the interviews. Several interviewees noted their evolution from church consumer (some had been raised in the UU faith), to social activist through the church, to leader within its governance structure.

On father who lost his son to suicide said, "I learned about my son's death while I was on my way to vacation. After calling my son's mother, the next person I called was our Senior Minister. She gave me the most meaningful message. She said, 'you have been giving so much to this community. Now it's time for us to take care of you.' This message was transformational."

These core interview themes, science, community, social justice, and reciprocity, provide a framework with which to consider mental health promotion and suicide prevention.

\subsection{Thoughts on Suicide as a Crisis of Spirituality}

When posed with the question of suicide as a crisis of spirituality, several interviewees were quick to note the many medical factors as well as mental health crises contributive to suicidality, such as post-partum depression, traumatic brain injury, chronic pain and so on. Interviewees acknowledged the brain-body connection as well as research behind mood fluctuation as well as how an individual's problem-solving capacity is associated with brain health. 
Some were also able to talk about the spiritual underpinnings of questioning the value of one's own existence. They noted that spirituality is hard to define; how many people have different definitions. However, most considered spirituality as a reflection on "who am I, and how do I connect to things like to myself, to my community, to my history, and to the universe."

Themes that emerged from this part of the interviews included:

Inability to Make Meaning: When we are unable to create a meaningful narrative around the chaos of our lives, a spiritual crisis can emerge. Looking at our lives through a lens of constructing purpose helps us find redemptive constructions out of our life challenges.

One minister stated, "[Being suicidal] is about not seeing a meaningful path forward—spiritual work is about meaning making. People become suicidal when they look at their lives and just feel stuck. We often talk about 'way' will open, 'way' will open.' Sometimes 'way' doesn't open but it closes behind some other things, and that is just effective. Sometimes we experience depression because we are living a life that isn't ours. We keep running into these walls."

Another participant noted, "Some of our folks are straight atheist—life doesn't have a larger meaning, it just is."

Lacking and Longing: One interviewee articulated the crux of the spiritual crisis as the interplay between consolation (longing) and desolation (lacking), "The spiritual crisis is ... there is nothing, it will be dark and painful forever. They can't see possibility. When you are just really focused on what you are lacking - as long as you are there, you can't figure out what you are longing for."

One Senior Minister emphasized that the heart of the JUC community is unconditional love and acceptance, “Our culture tells us-we can't be smart enough, successful enough, rich enough. It tells us we are our resume, our house, our clothes. Even if you've had a perfectly functional family, the erosion of our soul is constant. My goal is to affirm people and remind them, you are among the group that gets inherent worth and dignity, even on your worst day. There is some stainless part of your soul that is birthed by and steeped in love. You are loved and lovable because of who you are not in spite of it. Every time I say that, I see someone cry."

Ultimate Isolation: When people feel disconnected from something bigger than themselves, they often question their purpose. As one interviewee said, "If you lose connection to greater life force your depression and suicidality is exacerbated. You can get lost in the tunnel of depression because it is hard to see outside yourself. You can't recognize that your suicidal behavior is not getting rid of pain, it's just giving to others. When you are able to focus on alleviating someone else's pain through service, this act is the most uplifting thing for your own soul."

One minister noted, "One of the things we don't appreciate enough is that back 1000 years, there were only a handful of cities with more than 50,000 people. Most lived in country side villages, and on a typical day you wouldn't encounter someone you didn't know. Today, we cross paths with hundreds of thousands of people we will never see again. We tend to see each other as obstacles-people are just in our way. We are thrown together. It's a lonely crowd."

By contrast, the power of community is a strong spiritual deterrent to suicide. Some interviewees discussed the power of being fully present and empathic to another's pain, "It is deeply spiritual to be in the presence of someone who knows how it feels because they've been there."

One interviewee noted, "We hold hands at the end of each worship service. We feel 'this is my tribe, these are my people.' Many members can go all week without a human touch, then at the end of the service two people take your hands. At the closing words hands gently squeeze, 'I got you.'"

\subsection{Challenges Faced by JUC When Addressing Mental Health and Suicide}

Thwarted Emotional Expression: White, European-American, and middle-class comprise the normal demographics within Unitarian Universalism, including within JUC. These demographics and cultural heritages bring with them a sense of stoicism and individual determinism. Other cultures may value collective identities and accomplishments; however, this privileged community holds that an individual's destiny is largely the result of their own efforts and talents. Thus, instead of reaching 
out for community support, many members rely solely on their own internal resources of grit and perseverance. Generally, the cultural value is a sense to "do it alone" with an outward display of confidence and competence.

As one minister stated, "We tend to want to fix what is out there as distraction from what is inside or as for salve for what's inside. That's a mistake-we need to tend to what's within us. And we need to get out of the business of judging emotions as good or bad. We have a tendency to think mental health is about achieving balance as a stable state. Things don't work that way in nature; it's more give and take. If you are perfectly upright and balanced you will always be falling. So many people come to me and apologize for crying in front of me. I tell them, 'If you can't cry here with me, you never have permission to cry.' When we judge good and bad emotions we cheat ourselves out of the fullness of our lives and others out of their full expression. In other words, we wrestle with our injuries."

Shame and Stigma: As open-minded as the UU faith prides itself on being, there is a reluctance to be viewed as someone in need. UUs see themselves as helpers, as one of the UUs most commonly sung hymnals states, "We'll build a land, where we bind up the broken."

Because JUC is activated by social justice, members are drawn to the idea of "fixing other people's problems"; however, members seldom disclose their own struggles.

One minister commented on how he responds to families within the faith community, working through their own shame of the suicide death of a loved one, "Sometimes families find it important to name what had happened. Sometimes families hold shame-based theologies. I follow the needs of the family; we have to navigate how to proceed together."

Because of a reluctance to express vulnerability, people can be challenged to experience vulnerability in this public space, thinking, "I can't go to church now, because I don't have it together."

One interviewee said, "We don't want to be identified as the family with this problem. We don't want this to define us-we are doers, givers, and accomplished people."

\subsection{What Are Some Promising Practices at JUC that Contribute to Suicide Prevention?}

Interviewees offered many positive ways JUC contributed to upstream, midstream and downstream suicide prevention-from specific weekly rituals and religious education practices, to life transition support to special groups. As the community has grown and evolved, the church adapted these practices over time.

\subsubsection{Faith Community Transitions}

Maintaining Connectivity during Faith Community Transitions: As JUC has grown over the 12 years examined in this case study, keeping people connected in meaningful ways became increasingly challenging. Creating opportunities for smaller, more intimate communities often required hit or miss experimentation. This type of bonding and trust-building sharing does not easily happen at 100-person community dinners but does happen in smaller covenant groups and smaller religious education experiences.

One senior minister noted, "We needed to provide smaller networks that fostered enduring and strong friendships. When it comes to crises, we are much more likely to know when someone is in trouble through these closer circles."

Over the years, a membership survey sought to gather information about the congregation's needs. An open-ended question asked, "What keeps you coming?"

This senior minister replied, "It didn't surprise me-'the community' came up more than all other responses combined every year. We're in the religious community business, if we take care of that we will be fine." 


\subsubsection{Weekly Practices}

Weekly rituals also help the community integrate spiritual and emotional health. For instance, the practice of chalice lighting was one of the most commonly mentioned JUC practices that supported a culture of spiritual and emotional wellness. The chalice lighting ritual at JUC signifies the start of each Sunday service, as a member of the JUC community volunteers to share a personal story connected to the theme of the service. At the end of the story the volunteer lights the chalice in honor of some form of hope and healing. Through this practice of disclosed lived experience with hardship, the power of vulnerability is modeled within the religious context.

One senior minister reflected on this practice, "Members are telling a story from their brokenness, not from a scholarly perspective. The key learning is hearing the vulnerability. In this we see ourselves."

Another practice that supports emotional healing are the weekly pastoral prayers. At each service, ministers acknowledge that members are in different emotional places by celebrating the joyful experiences of the members and acknowledging their sorrows, including the sorrows of depression and suicide. Even within youth religious education rituals, children are encouraged to put emotional words to their experiences.

One minister mentioned, "I am proud of how we have evolved in our ability to enter a spirit of prayer with one another. More people are closing their eyes and demonstrating a willingness to go inward and experience a feeling of being held. I see people experience 'it's okay for me to bring my worries here. My community is shouldering this with me.'"

Interviewees mentioned that ministers were not afraid to integrate topics related to emotional health into worship services. Some of the Sunday service themes have included "A Song of Hope," "Becoming Ourselves," and "What Do We Want?" These worship services and others have touched upon the interplay between emotional and spiritual health.

In addition to the weekly rituals, practices and themes of the shared JUC Sunday services, on-going religious education, especially curricula designed for youth help bridge emotional and spiritual growth. For instance, several interviewees commented on how the youth religious education curriculum set a foundation for positive relationships and a chance for self-discovery. For example, the "OWL" program (Our Whole Lives) educates adolescents and young adults about values, sexual health, and relationships. Part of the curriculum is designed to help participants feel comfortable exploring their gender identity and sexual orientation by starting a discussion when they are in 4th grade and bringing up the topics again in 7th grade. Given the high rate of suicidal thoughts and behavior among both sexual minority youth (Trevor Project n.d.; Clements-Noell et al. 2018) and youth experiencing sexual trauma (Wherry et al. 2013), the hope is that this open and honest conversation about sex, sexuality, and sexual identity at an early age will help to build a stronger sense of self when these issues and experiences become more prominent later in life.

\subsubsection{Youth Religious Education}

Another example of a year-long youth religious education curriculum is The Coming of Age program. This program matches 8th grade teens with an adult mentor who helps their mentee to develop their own spiritual path. Over the course of the year, many activities are designed to build trust bonds with other caring adults and allow the teens to experience rites of passage while sitting before their "tribal elders."

One Coming of Age leader explored the process of creating "Circles of Supports" by building relationships based on trust and deeper bonds: "We help them identify who is in their Circle of Support. We explore the fact that sometimes the person most likely to be a reliable source of support is not the person you saw last or see most often. We help them identify-who are your 3 o'clock in the morning friends? Your 3 o'clock in the morning friends are different than regular friends. It's a whole other level of commitment. You should always have someone you consider your 3 o'clock in the morning friend." 
Because of the research (Wyman et al. 2010) that supports the power of caring adults to effectively support and refer teens who are suicidal, this program is promising in its ability to help youth develop a stronger safety net.

Finally, the last example of youth religious programming offered by the interviewees as an example of a resilience-building experience is what JUC called "The 9th Grade Trip." When in the 9th grade, teens from all Unitarian Universalist communities in Colorado and Wyoming come together for a year-long study of the Hopi and Navajo Nations. The year concludes with a 10-day journey to Arizona and New Mexico to experience indigenous culture firsthand, connect with the people who live there, and appreciate their history and current ways of life. This experience is intentionally not a "community service" trip, but rather a "community engagement" experience that gives the youth from both the UU and indigenous communities a chance to get to know each other. The year-long learning experience happens during facilitated classes and retreats and the exchange of letters among the youth before the trip. This in-depth learning helps teens to connect to something bigger than themselves and appreciate the impact of historical trauma on other communities.

Additionally, these experiences help the youth forge a strong sense of belonging with their peers (youth from the UU churches and the indigenous communities) and with trusting connections to caring adults. The environments created allow for a safe space to discern important life questions about identity and spiritual beliefs in a non-threatening environment.

\subsubsection{Pastoral Care and Memorial Services for Suicide}

Another promising practice offered at JUC is Pastoral Care. According to the Unitarian Universalist Association, the goal of pastoral care is to provide a "ministry of hope and caring" to prevent isolation and suffering which is often a consequence of illness, crisis, or loss.

At JUC, the Pastoral Care Team is a group of caring volunteers who offer compassion and practical assistance as they "companion" people for a time. The group is supervised by a JUC Minister and meet regularly. They build relationships with trusted community mental health resources and refer individuals to these resources when the mental health needs of members exceed their capacity. The Pastoral Care Team also supports people in spiritual crises through jointly discussing works like Viktor Frankl's “Man's Search for Meaning” (Frankl 1946) and Pema Chodron's “When Things Fall Apart: Heart Advice for Difficult Times" (Chodron 2000).

All of the ministers interviewed mentioned how presiding over suicide funerals really opened their eyes to the tragedy of suicide and how complicated the services often were. The leadership demonstrated during these immensely sorrowful times reflects the best practices offered to clergy by groups like the Suicide Prevention Resource Center, such as balancing the celebrations of the life that was lived without shirking away from the tragedy of the death (Suicide Prevention Resource Center 2004).

One senior minister described how challenging eulogies for suicide can be, "I sought to tell the truth, to honor the life that was lived and acknowledge the devastation of suicide, especially for someone who has done amazing things and when others are susceptible. Suicide wasn't their whole life. There was joy, and suicide is awful. It is hard to strike the balance. Suicides are different than other end of life of celebrations. Sometimes the death was clearly a suicide, some were unclear, especially overdoses. People were enormously grateful for the support and honesty. They don't want person demonized or made into something they were not. Family and friends are in such need, feeling guilty. Constantly haunted by "what did I fail to do or how did I trigger it?'”

Another minister commented, "Many people in JUC have been touched by suicide. Elder adult parents. Children. Siblings. There is not a day that it's not with you. Memorial services are a lovely and painful intersection, where people are in pain and open to larger truths."

A father who had lost a son to suicide said this about his experience, "I was open, and JUC welcomed it. There were no elephants. Not even little mice. We all needed to talk about it. When I came home after the service. I noticed my arms ached from hugging so much. What a glorious hurt this was." 


\subsubsection{Covenants and Sub-Communities}

An additional promising practice identified by the interviewees was the power of intimacy of small groups fostered by the faith community. JUC is a relatively large congregation, and interviewees noted that smaller groups provided a more intimate form of support. Some special groups were noted:

Mental Wellness Advocates: Over the years, several special groups have emerged organically out of congregants' passions and needs. One such group calls themselves the "Mental Wellness Advocates." This group strives to educate JUC members about mental health, developing ways for the JUC community to support those dealing with a mental illness whether in themselves, a family member, or friend. When they first launched, a founder recalled, "We filled a room. Most people said 'I've not talked about [my mental health issues] before.'" Since the launch the group has been responsible for hosting many of the special events listed below.

Mother-Daughter Support: Another group that emerged was a mother-daughter group which met regularly to discuss how society can be toxic to teenage girls. The mother-daughter pairs came together to address difficult topics in a group setting. By listening to other mothers and peers respond, trust was built.

Covenant Circles: Small group ministry in the form of covenant circles has also been very helpful to members. Members who commit to this format learn listening skills, how to commit to one another, and the importance of confidentiality.

\subsubsection{Special Events}

Interviewees also noted that some of JUC's special events helped to foster mental health literacy, empowerment, compassion, and support, all of which contribute to various forms of suicide prevention.

Speakers and Trainings: By connecting with the local NAMI (National Alliance on Mental Illness) chapter, JUC was able to bring in an "In Our Voice" speaker to share lived experience perspectives on mental health. The church also offers Mental Health First Aid to both youth and adults. In addition, the local mental health center has visited the church to talk about different mental health diagnoses and services.

Social Action for Mental Health: A few times a year, JUC engages in community events related to mental health or suicide prevention. For instance, JUC participated in "Together Colorado," a social justice forum on mental health/suicide prevention and schools and talked openly about concerns in a town hall format.

JUC groups also participate in community walks for mental health and suicide prevention. One senior minister recalled, "I participated in the suicide prevention walk. It reminded me of being queer in 80s when it was not okay. [The 80s] was a time of AIDS and discrimination, and out of that we had the quilt project. These people who died had names and people who loved them. The suicide prevention marches do the same thing. In those last moments, the people couldn't feel that loved. It couldn't reach them--such a robust tragedy."

Special Worship Services: The Holiday Healing Candlelight Ceremony is an annual tradition held approximately during the second week of December. The ceremony originated primarily as a place to support people bereaved by suicide and other forms of death, but it has evolved over the years to something broader. The current purpose of this interfaith ceremony is to provide a place to hold pain, loss, and struggle during a time of year when so many are celebrating. Music and reflective practices are central to this contemplative service.

\subsection{What Are the Lessons Learned and Future Directions for JUC?}

A few interviewees mentioned the downsides of the UU faith. As mentioned early JUC is a community of highly educated and achievement-oriented individuals; thus, JUC members want to be self-sufficient. Although they are willing to help others, they are unlikely to ask for help themselves. 
Because of the pervasive on-going stigma regarding mental health challenges and suicide, many people are reluctant to disclose their own stories. Thus, moving forward, many interviewees suggested additional anti-stigma work is needed to challenge the stereotypes and misinformation that remains and to let members know that all members need support from time to time.

Additionally, inclusivity may not be experienced equally across all demographics. One participant commented, "We've (JUC) been good at welcoming transgender people and those on the LGB spectrum, but not as great on welcoming people who are living with chronic mental illness or in addiction recovery."

Because the community also values personal freedom and self-determination, the faith community may be overlooking destructive sexual addictions such as pornography addiction. This may result from the UU community's desire not to impose a moral judgment on sexual behavior.

In other ways, the UU's approach of boundless personal exploration can be overwhelming to many. One interviewee said, "Individualism can be intimidating. If you don't have character psychic structure. If you don't know who you are, you can get overwhelmed. JUC demands that you push back on ideas, follow own internal guides, and seek sources of inspiration. That can be too much for some. By contrast, when someone comes to your door and reads scripture with you, it can be comforting when you are overwhelmed."

Several interviewees looked forward to the next steps in the evolving mental health strategy at JUC and longed for church leadership to more explicitly normalize the spectrum of mental health challenges from the pulpit.

One future direction that was identified through this process was how best to prepare ministerial staff to look out for one another and their own mental health or suicide challenges. Faith community leaders often find themselves "of a community but not in it" because of their role. This can often be a very lonely experience. When a minister dies of suicide, the surviving congregation is often shattered on many levels and few communities have a plan on how to pull themselves out of such a crisis.

\section{Discussion and Conclusions}

JUC strives to be strategic in integrating spiritual and emotional health and support; however, the community still has more steps on its journey to evolve into a welcoming place for all people experiencing mental health and suicide challenges. Nevertheless, the lessons learned from 2004 to 2017 provide a great template for other faith communities to emulate.

This case study explored the "Upstream, midstream, and downstream" approaches to suicide prevention evident throughout the lifecycle of JUC's members. The advancements are a result of leadership—formal and informal — that pushed aside silos of traditional religion and mental health services and experimented with new ideas on what might be possible within a faith community.

Unconditional love, gratitude, and community are specific ways JUC prevents suicidal despair through resilience. The church appears to be strongest in these upstream efforts to build reservoirs of strength from youth to old age.

However, midstream approaches to suicide prevention have proven to be more challenging. As the church grows upwards of 1000 members, early identification of and intervention for emerging mental health concerns becomes more difficult. It's hard to be visible in a crowd; accordingly, smaller group programs for youth and adults are an important way JUC can create safe spaces for vulnerability and compassion.

Downstream suicide prevention approaches are also evolving. As the church learns how best to respond to mental health crises and suicide, many are resisting the instinct to pull away. Instead, members are intentionally leaning in to learn how best to support others in their darkest hour. Additional training and candid discussions among staff, volunteers, and members help the church continually improve its ability to be a part of the community safety net.

This case study has many limitations and methodological short-comings to be considered. First, the sample size of the interviewee pool was very small and senior leaders (ministers and board 
presidents) were overly represented. Second, despite intentions to include someone with personal lived experience with their own mental health or suicide crisis, only family members and caregivers responded to the interview request. This outcome may be indicative of the dynamic mentioned earlier: how community members prefer to be identified as helpers rather than people needing help. Finally, the interviewee responses were not recorded verbatim or coded among multiple raters, increasing the likelihood of observer bias.

In summary, faith communities can play a distinctive and influential role in helping people integrate their spiritual and emotional selves, and ultimately prevent suicide. Aspects of a faith tradition's core beliefs, the structure and practices of the faith experience, and the connection of the faith community contribute to how people build resilience and cope with unimaginable mental anguish and despair. Jefferson Unitarian Church offers one story of how a faith community can pull together to build collective psychological hardiness and offer a softer place to land when life brings people to their knees.

Conflicts of Interest: The authors declare no conflict of interest.

\section{References}

American Foundation for Suicide Prevention. n.d. Suicide Statistics. Available online: https://afsp.org/aboutsuicide/suicide-statistics / (accessed on 27 December 2017).

Bonelli, Raphael, Rachel Dew, Harold Koenig, David Rosmarin, and Sasan Vasegh. 2012. Religious and spiritual factors in depression: Review and integrated of the research. Depression Research and Treatment 2012: 962860. [CrossRef] [PubMed]

Chodron, Pema. 2000. When Things Fall Apart: Heart Advice for Difficult Times. Boulder: Shambhala.

Clements-Noell, Kristen, Taylor Lensch, Amberlee Baxa, Christopher Gay, Sandra Larson, and Wei Yang. 2018. Sexual identity, adverse childhood experiences, and suicidal behaviors. Journal of Adolescent Health 62: 198-204. [CrossRef] [PubMed]

Colucci, Erminia. 2008. Recognizing spirituality in the assessment and prevention of suicidal behavior. World Cultural Psychiatry Research Review 3: 77-95.

Doty, Timothy, and Sally Spencer-Thomas. 2012. The Role of Faith Communities in Suicide Prevention: A Guidebook for Faith Leaders. Westminster: Carson J Spencer Foundation, Inc.

Frankl, Viktor. 1946. Man's Search for Meaning. Boston: Beacon Press.

Joiner, T. 2006. Why People Die of Suicide. Cambridge: Harvard University Press.

Krysinska, Karolina, Danielle Jahn, Sally Spencer-Thomas, and Karl Andriessen. 2017. The roles of religion and spirituality in suicide bereavement and postvention. In Postvention in Action: The International Handbook of Suicide Bereavement Support. Edited by Karl Andriessen, Karolina Krysinska and Onja Grad. Boston: Hogrefe, pp. 186-96.

National Action Alliance for Suicide Prevention. 2017. Faith. Hope. Love. Celebrating Reasons to Live. Available online: http:/ / actionallianceforsuicideprevention.org/ faithhopelife (accessed on 12 March 2018).

Oxford English Dictionary. n.d. Definition of Resilience. Available online: https:/ / en.oxforddictionaries.com/ definition (accessed on 31 March 2018).

Phend, Crystal. 2009. APA: Religious Attitudes Influence Suicide Risk. MedPage Today. Available online: https: / / www.medpagetoday.com/meetingcoverage/apa/14324 (accessed on 31 March 2018).

Prouty, Dick, and Dee Ray. 2009. A History of Jefferson Unitarian Church from 1959 to 2009. Available online: https: / /drive.google.com/file/d/0Bz-pEA5x7_pMRHZyQ0xZMEhfenM/view (accessed on 28 December 2017).

QPR Institute. n.d. QPR for Clergy. Available online: https:// courses.qprinstitute.com/index.php?option=com zoo\&task=item\&item_id=69\&Itemid=101 (accessed on 31 March 2018).

Spencer-Thomas, Sally. 2010. Suicide and Spirituality Part I: The Roles of Faith and Faith Communities. Available online: http:/ / sallyspencerthomas.blogspot.com/2010/10/suicide-and-spirituality-part-i-roles. html (accessed on 28 December 2017).

Spencer-Thomas, Sally. 2016. Construction and Suicide Prevention: 10 Action Steps Companies Can Take to Save Lives. CFMA. Available online: http://s3.amazonaws.com/rdcms-cfma/files/production/public/ ConstSuicPrev10ActionSteps.pdf (accessed on 28 December 2017). 
Suicide Prevention Resource Center. 2004. After a Suicide: Recommendations for Religious Services and Other Public Memorial Observances. Newton: Education Development Center, Inc.

Trevor Project. n.d. Preventing Suicide: Facts about Suicide. Available online: https: / / www.thetrevorproåject. org/resources / preventing-suicide/facts-about-suicide/\#sm.0001hetq9ol1nfljvla1ti2bdh2uv (accessed on 15 March 2018).

Unitarian Universalist Association. 2014. The Largest Congregations in the Unitarian Universalist Association-2014. Available online: https://www.uua.org/sites/live-new.uua.org/files/documents/ congservices/largecongs/largest_congs.pdf (accessed on 28 December 2017).

Unitarian Universalist Association. n.d. Beliefs and Principles. Available online: https://www.uua.org/beliefs/ what-we-believe (accessed on 28 December 2017).

Wherry, Jeffrey, Spenser Baldwin, Kacee Junco, and Belinda Floyd. 2013. Suicidal thoughts/behaviors in sexually abused children. Journal of Child Sexual Abuse 22: 534-51. [CrossRef] [PubMed]

Wu, Andrew, Jing-Yu Wang, and Cun-Xian Jia. 2015. Religion and completed suicide: A meta-analysis. PLoS ONE 10: e0131715. [CrossRef] [PubMed]

Wyman, Peter, Hendricks Brown, Mark LoMurray, Karen Schmeelk-Cone, Mariya Petrova, E.rin Walsh, Xin Tu, and Wel Wang. 2010. An outcome evaluation of the Sources of Strength Suicide Prevention Program delivered by adolescent peer leaders in high schools. American Journal of Public Health 100: 1653-61. [CrossRef] [PubMed]

(c) 2018 by the author. Licensee MDPI, Basel, Switzerland. This article is an open access article distributed under the terms and conditions of the Creative Commons Attribution (CC BY) license (http://creativecommons.org/licenses/by/4.0/). 